\title{
Analysis of the Impact of Cereal Product Import-Export on GDP in Romania
}

\author{
Geanina COLAN ${ }^{\star}$, Tincuta VRABIE ${ }^{\star \star}$, Aura COLAN ${ }^{\star \star \star}$, Laurentiu COROBAN ${ }^{\star \star \star \star}$
}

\begin{tabular}{l}
\hline \multicolumn{1}{c}{ A R T I C L E I N F O } \\
\hline Article history: \\
Accepted December 2019 \\
Available online December 2019 \\
\hline JEL Classification \\
Q13 \\
Keywords: \\
Cobb-Douglas function, Non-linear \\
regression, R language, Cereal \\
products import and export
\end{tabular}

1. Introduction

Imports and exports are a fundamental part of the economy of any country. These two economic macroindicators directly influence GDP. Specialised literature mentions a strong correlation between the increase of GDP and the increase of exports, as well as the negative influence on GDP increase exerted by imports. In this context we decided to explore the connection between cereal exports and imports and the GDP of Romania.

In our country the cereal product market is dynamic and diverse, and enjoys great importance in developing both the agricultural sector and the food industry. The area cultivated with cereals in Romania at the end of 2018 was 8.5 million hectares, i.e. $39.5 \%$ of the total surface (Report on Romanian agriculture, 2018).

From the point of view of the degree of cereal cultures, Romania is above the European average of $38 \%$, being on the 11 th position. The branch of agricultural economy contributes a total of $6.5 \%$ of the GDP, out of which the cereal sector has a direct contribution of 3.1\%-3.5\%, according to PwC Romania. The same agricultural sector accounts for $8.5 \%$ of the exports, estimated at more than 5 billion euros. Taking into consideration these aspects, it may be said that the cereal sector is quite important in the economic development of our country, since cereals and cereal-based processed products are to be found in all areas of activity. In this context, this market should be managed and exploited in a sustainable manner, and at the same time able to meet the demands of the consumerist society of today.

\section{Purpose and objectives}

The purpose of the paper is to perform an econometric analysis of the values of imports and exports of cereal products - as independent variables, and the values of GDP - the dependent variable, within the interval 1999-2016. What the authors intended was to create an econometric model able to allow foreseeing the evolution of the country's economy, taking as a reference point the macroeconomic indicator GDP, depending on the increase or decrease of the imports and exports of cereal-based products.

The objectives of this study are the analysis of the data collected within 1999-2016, finding an econometric model, namely the influence of import and export on the GDP of Romania, as well as data 
processing by the Rstudio program. This program performs data processing by means of the R Language, specialised in database analysis.

\section{Literature review}

"The Gross Domestic Product (GDP) is a macroeconomic indicator reflecting the sum of the market value of all goods and services destined to final consumers, which are produced in all the branches of a country's economy within a year" (Jemma, D., V, 2012). GDP is a macroeconomic indicator which clearly reflects the evolution of a country's economy. In Romania GDP is calculated for various periods of time, like a term or a year.

Export is a commercial operation whereby a part of the goods produced, processed, completed or repaired in a country are is sold on the market of other countries. Export is an important part of the economy, having a defining impact (Macovei, A. G., Balan, I., 2009). The values of export are closely connected to a country's production. The export of goods is tightly linked to the economic structure and development level of companies involved in this process. Exports allow companies to develop and diversify products and services in order to match the market demand as closely as possible. Due to their importance, exports or the export area is a large part of a country's economy. Thus, in the European Union 2010 and 2017, jobs in this particular sector accounted for $10.3 \%$ of the total, reaching $14 \%$ in 2018.

In Romania foreign trade has undergone many changes recently. One major change occurred in 1990 after the change of the political regime, and another notable change happened in 2007, when Romania joined the European Union.

Imports constitute the totality of commercial operations introducing in the country merchandise/ products purchased in a different country. Imports are a part of the economy that directly influences the GDP, as they are connected to the country's production: if production is high, then imports are low, and if the production decreases, and the consumers' needs are constant, then imports need to increase.

Imports, unlike exports, reflect the economic weaknesses of a country. The needs of a nation that are not met by its own domestic production are made up for by means of imports. But this means the creation of a dependence upon the export ability of another country. In some cases, high reliance on imports creates a higher variability of the positive effects on the long-term welfare of a country. In other words, imports may have positive effects on short term, as they may compensate certain annual deficiencies produced by various causes, but on long term, unless the country's own production undergoes an increase, unfavourable effects may occur.

In the case of Romania, imports are higher than exports. In 2018, exports increased by $10.1 \%$, and imports by $13.2 \%$, as compared to 2017 .

The production function was developed by the American economists Paul Douglas and Charles Cobb in 1928 (Macovei, A. G., Siretean, S. T, 2017). This function is a model of multiple non-linear regression of the log-linear type, generating the log-linear model at a number k of independent variables (Bănică, E., Vasile, V., Boboc, C, 2018). The model devised in the present paper contains a dependent variable, GDP, and two independent variables, cereal product imports and exports.

The Cobb-Douglas production function uses as variables the imports of cereal products $\left(i m p \_t\right)$ and the export of cereal products (exp_t) which are the main factors of production increase. The Cobb-Douglas production function may be expressed as:

$$
P I B=\beta \cdot i m p \_t^{\alpha_{1}} \cdot \exp _{-} t^{\alpha_{2}}, \alpha_{1}, \alpha_{2} \in[-1,1], \beta>0,(1)
$$

where:

- $\beta$ is the regression coefficient or the average value of the dependent variable GDP when imp $\_t=\exp \_t=1$;

- $\alpha_{1}, \alpha_{2}$ are the regression coefficients or the elasticities of the dependent variable in relation to each independent variable,

$$
\alpha_{1}=\frac{i m p \_t}{P I B} \frac{\partial P I B}{\partial i m p \_t}, \alpha_{2}=\frac{\exp \_t t}{P I B} \frac{\partial P I B}{\partial \exp \_t} .(2)
$$

The Cobb-Douglas production function is a multiple regression non-linear function.

The total elasticity in relation to the imports and exports of cereal products results from the relation:

$$
\hat{\alpha}_{1}+\hat{\alpha}_{2}
$$

If $\hat{\alpha}_{1}+\hat{\alpha}_{2}=1$, then the production variation is constant in relation to the two factors. 
If $\hat{\alpha}_{1}+\hat{\alpha}_{2}>1$, then the production variation is accelerated in relation to the two factors.

If $\hat{\alpha}_{1}+\hat{\alpha}_{2}<1$, then the production variation is low in relation to the two factors.

$\mathrm{R}$ Language is a language and a medium for statistic calculus and graphic representation. $\mathrm{R}$ Language provides a wide range of statistical methods (linear and nonlinear modelling, classic statistical tests, time analyses, classification, grouping, etc.) and graphic techniques, and is very extensible, its use being limited by the user's abilities (Jula, D., Jula, D, 2018). R Language has an integrated range of software facilities for data handling, calculation and graphic display. R Language includes: an efficient unit of data handling and storage, a large and integrated collection of intermediary tools for data analysis, graphic facilities for data analysis and display, electronically or in writing, and a well-developed, simple, and efficient programming language which includes conditionalities, loops, recursive functions defined by the user and input-output facilities. $\mathrm{R}$ Language is an intuitive language, so that it is accessible to people without specialised IT training. An important aspect of this programming language is that it does not need to draw up an entire program (as it is the case in $\mathrm{C}, \mathrm{C}++$, Fortran, Pascal) to be able to execute commands. In the $\mathrm{R}$ Language each code line is executed individually. RStudio is an integrated development environment (IDE - Integrated Development Environment) for R. it includes a console, a syntax editor evincing the direct code execution, as well as tools for graphs, background, repairs and working space management (https://www.rstudio.com/products/RStudio).

\section{Research methodology}

In order to have a comprehensive view on the GDP, the present study took into account the relevant values within the interval 1987 - 2016, but the statistical analysis only used the values within the interval 1999 - 2016 (www.bancamondiala.com).

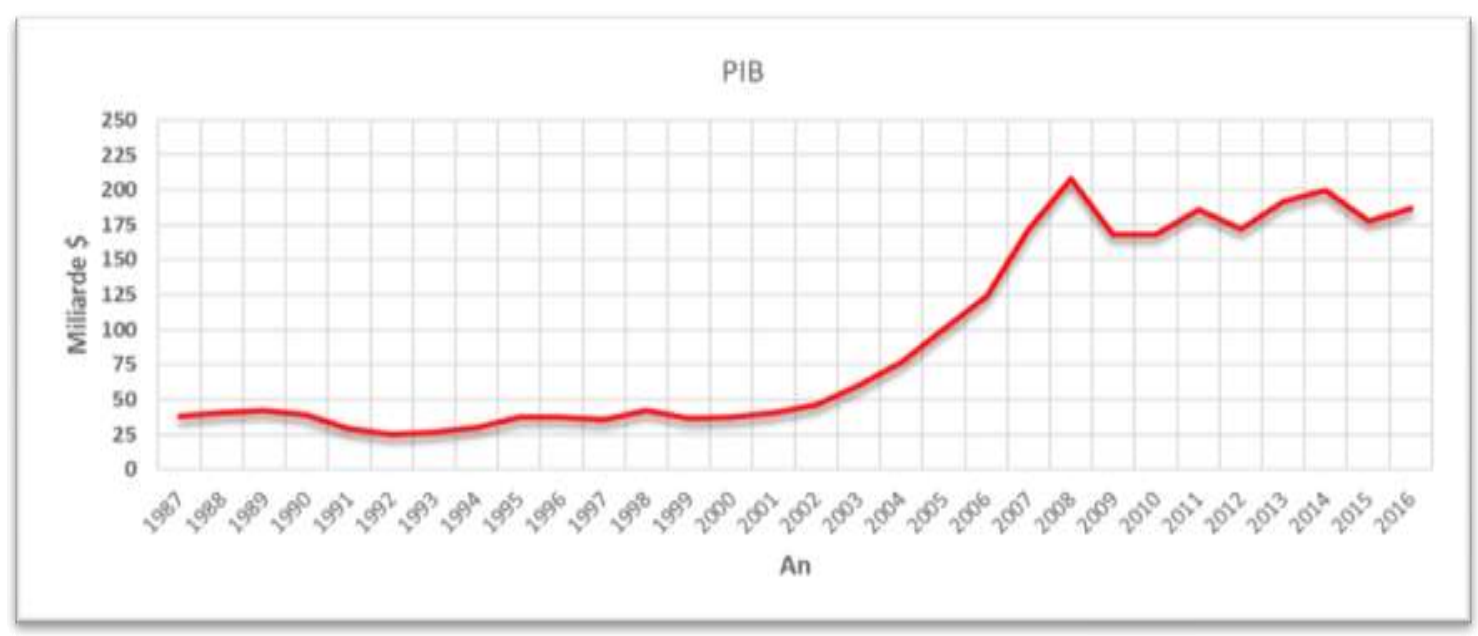

Figure 1. GDP evolution in Romania 1987 - 2016

Source: www.bancamondiala.com

The graph evinces the increase in the early 2000s, which reached a peak in 2008. In 2000 the value of GDP was $\$ 37.438$ billion, and in 2008 it was $\$ 208.181$ billion, i.e. a $456.06 \%$ increase. It may be said that it is one of the most spectacular increases in Romania's recent history. The sharp fall in 2009 corresponds to the year when the world economic crisis also affected Romania.

Out of the many products exported by Romania, the present study chose the most important cereal products. The data used in the econometric analysis are taken from http://www.fao.org/faostat/en/\#data/FT. 


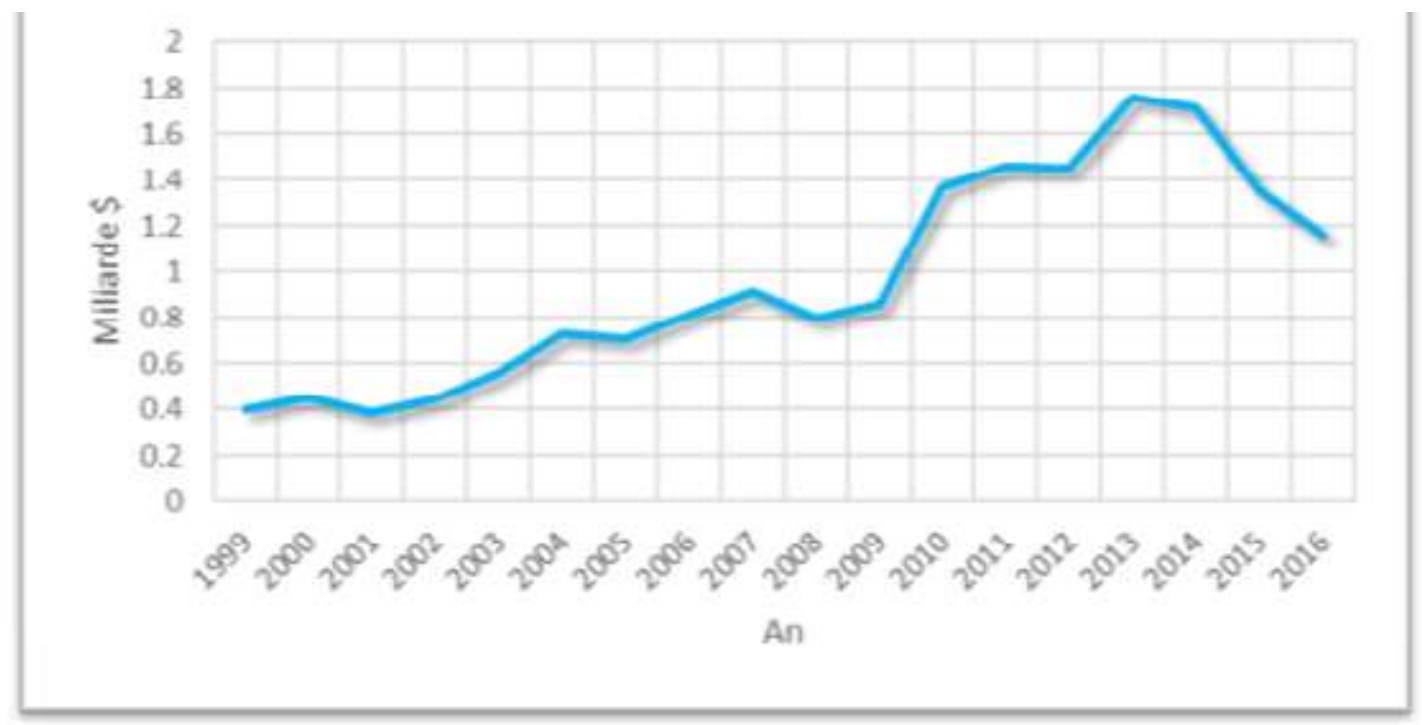

Figure 2. Total exports of cereal products 1999-2016 Source: http://www.fao.org/home/en/

One may thus see the upward trend of this indicator, starting in 1999 from the value of $\$ 0.39$ billion, to a peak in 2013 , with a value of $\$ 1.76$ billion, thus registering an increase of $347.73 \%$, i.e. an increase in the exports of cereal products of about 3.5 times. In 2014 and 2016 there was a sharp fall. According to PwC Romania, in 2014, Romania was the 9th most important processor and trader of cereal products in EU, contributing $3 \%$ of the total cereal products processed and traded in the European Union (420.4 bn m3). But taking into account the low degree of cereal processing in our country, this contribution may increase (PwC Romania, 2016). It is worth mentioning that there is a sharp difference from the value of $\$ 1.70$ billion in 2014 to the value of $\$ 1.15$ billion in 2016 , which means a decrease by $32.46 \%$, although Romania has a huge potential to develop its agricultural sector. These changes in the cereal exports may be a consequence of the change of cereal production in Romania.

Regarding the imports, raw material imports that can lie at the basis of a strong industry may generate a very powerful economic mechanism. Nowadays, Romania mostly imports auto parts and accessories, crude oil, medicines and antibiotics, cars, wires, cables, and other electric conductors. Out of the many products imported by Romania, we chose to analyse the cereal-based processed products in the present study.

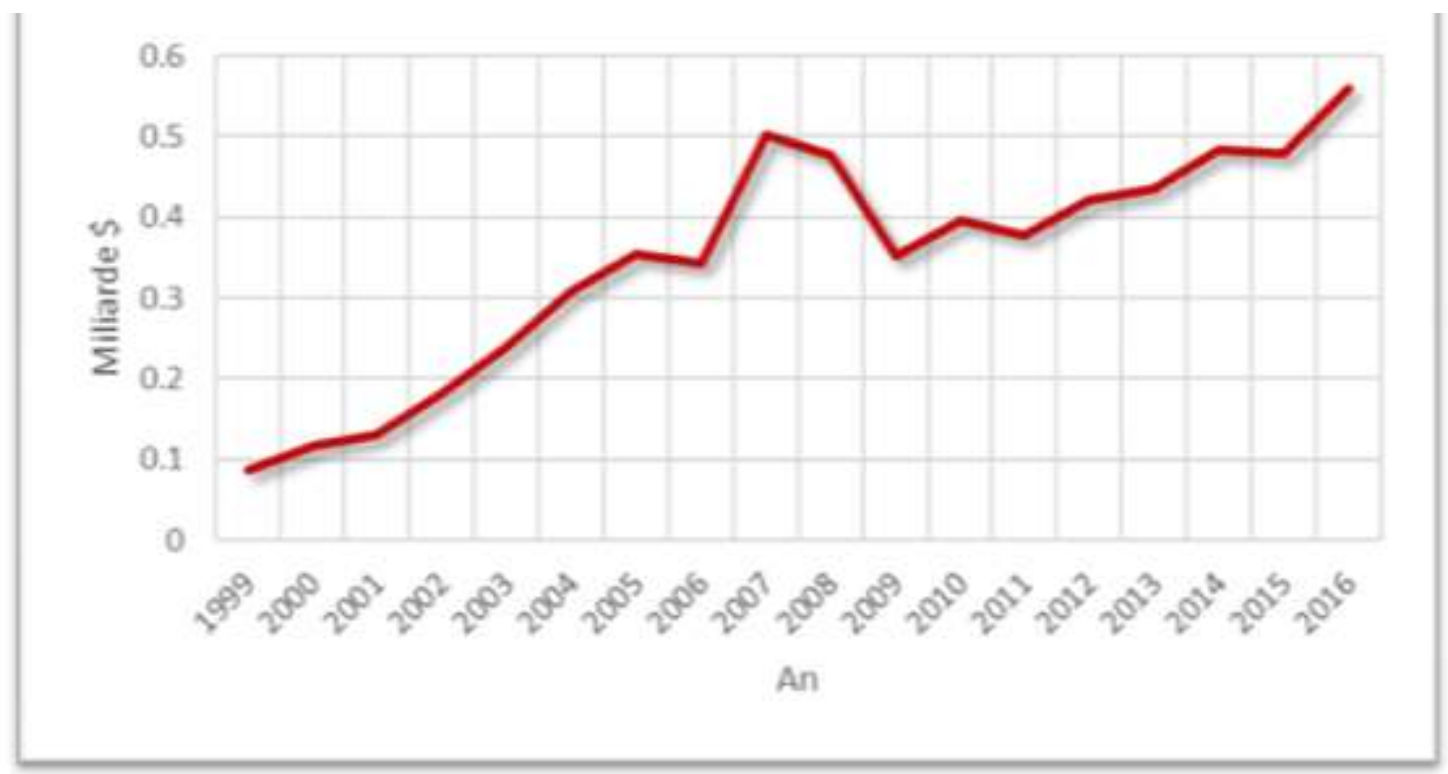

Figure 3. Total cereal imports within 1999-2016

It may be seen that the import value is on the increase. A peak was registered in 2007 as compared to 2006, with a $46.93 \%$ increase. This increase may be accounted for by Romania's ascension to EU, which eliminated a part of the customs duties. It is worth mentioning that 2007-2009 marked a period when imports fell dramatically, from $\$ 0.5$ billion in 2007 to $\$ 0.35$ billion in 2009, which is a $30.14 \%$ decrease. 
These import cuts may be accounted for by the fact that in 2008, and 2009 respectively, Romania was in economic crisis, and the country's entire economy was adversely affected by this phenomenon. The same happened to the processing industry using the main raw materials.

\section{Statistical data analysis}

The purpose of the analysis is to devise a model allowing to foresee the evolution manner of the country's economy, taking into account the macroeconomic indicator GDP, function of the increase or decrease of cereal imports or exports. The Cobb-Douglas function or the production function is among the most widely used tools in the economic environment. We chose this model as the exponential function best captures the manner in which GDP evolves under circumstances of economic growth.

In order to calculate the Cobb-Douglas production function the data were logarithmed, and the coefficients of the Cobb-Douglas function between GDP and the values of the cereal products imports and exports obtained after running the model are found in Table 1. In the RStudio program commands are executed at the command line: at the top of Table 1 one may notice the command sequence used.

Table 1. The coefficients of the Cobb-Douglas function

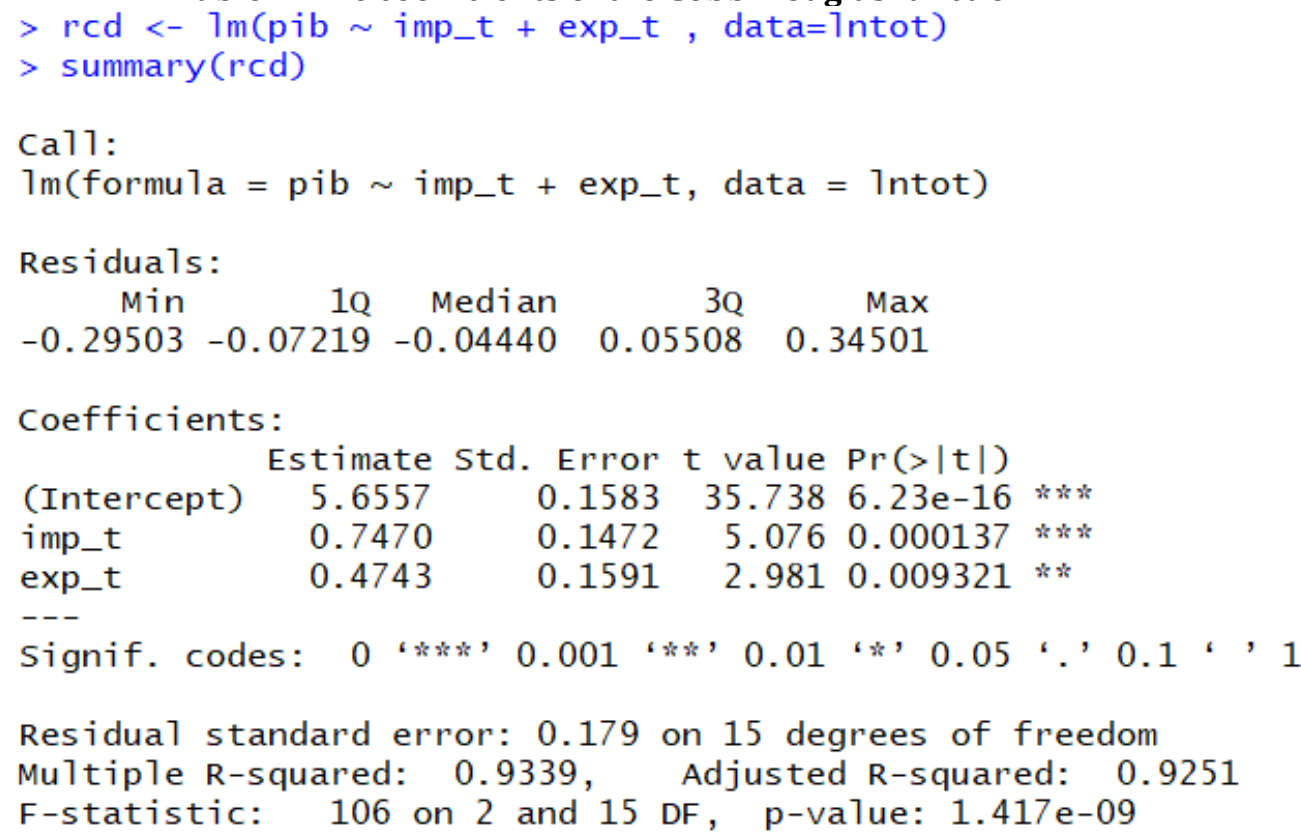

Source: data processing by the authors

According to Table 1, the values of the regression parameters are $\alpha_{1}=0,7470$ and $\alpha_{2}=0,4743$. Thus, according to the model adopted, the logarithmed production function will have the following form:

$$
\ln p i b=5,6557+0,747 \cdot \ln i m p_{-} t+0,4743 \cdot \ln \exp _{-} t
$$

The Cobb-Douglas function will have the following form:

$$
p i b=e^{5,6557} \cdot i m p_{-} t^{0,747} \cdot \exp t^{0,4743}
$$

Considering the Cobb-Douglas function obtained, it can be concluded that for a $1 \%$ increase of the cereal imports, the GDP increases by $0.747 \%$, and for a $1 \%$ increase of the cereal exports, the GDP will increase by $0.4743 \%$. according to the function obtained, the sum of the two indicators is 1.2213 , exceeding 1 , so the cereal imports and exports accelerate GDP increase. It is to be noted from the coefficient table (1) that the cereal import factor has a greater influence upon the GDP, the significance of the Std test, $0.000137(* * *)$ is lower than the assumed risk of 0.05 , as well as the higher value of the Std test ( $t$ _value $=5.076$ ). this could be accounted for by the lack of industry, although our country can boast the emergence of various agricultural structures that built farms, associations, etc., thus contributing to the economic development of the area, as well as to the export increase. It may be concluded that Romania exports almost the entire production of cereal products. 


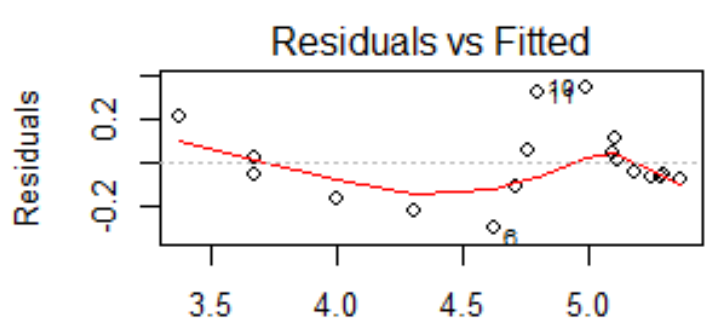

Fitted values

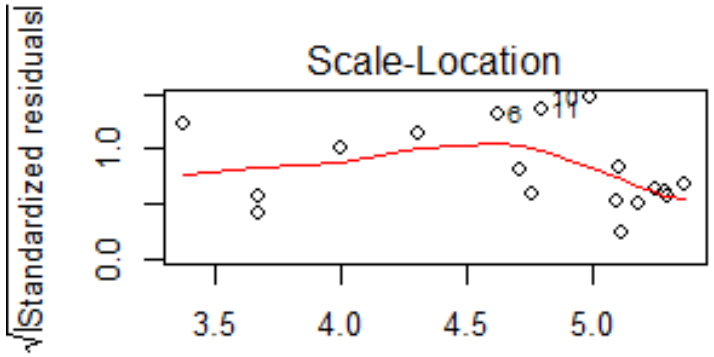

Fitted values
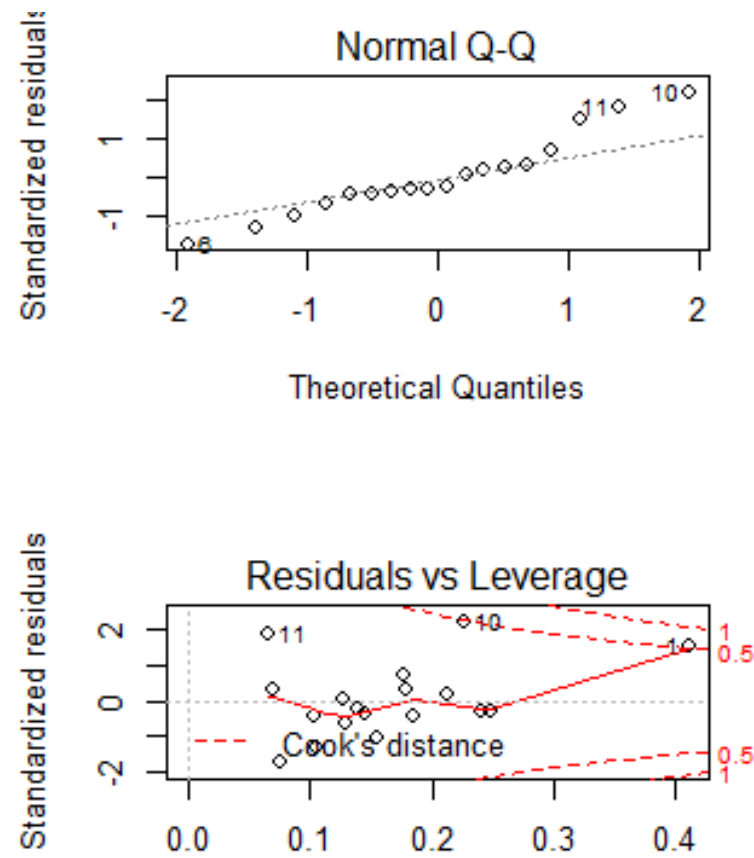

Leverage

Figure 4. Graphic representation of the Cobb-Douglas function Source: data processing by the authors

Figure 4 shows the graphical representation of the analysis of the regression model adopted. these graphical representations may be used to assess and perhaps improve the model. the initial graphical representation shows the connection between the residual values and the adjusted values. The residual values are the difference between the real and the values predicted by means of the regression equation. This graph tests whether the relation between the analysed variables is linear and there is equal variance along the regression line. In the situation under analysis one may note points outside the field, and these peak residual values correspond to the years 2008 and 2009. In other words, the adopted model is not as accurate for the values of imports and exports in 2008 and 2009. A possible cause may be that these are the years when the worldwide financial crisis began, and the main importers of cereal products from Romania exhibited a decrease in demand.

The Normal Q-Q graph is a probability graph determining if the dependent variables are normally distributed. If the values are normally distributed the graph will be distributed according to a linear function. In the case under analysis one may see that the values undergo a linear distribution. The value that shows the highest deviance is value no.10, corresponding to the year 2008.

The third graph, Scale-Location, shows that if the residue is spread equally along the regression line, this aspect refers to homoscedasticity, i.e. if at the level of conditioned distributions the error variance is constant. This model observes this requirement.

The bottom right graph shows the plot Residuals vs. Leverage, helping us identify the values that have a considerable influence on the model. These values with a high influence may be within or outside the normal domain. The values mentioned above are to be found in the top or bottom right corner outside the dotted red (Cook's distance).

$>$ anova(rcd) \# anova table

Table 2. ANOVA Table

Analysis of Variance Table

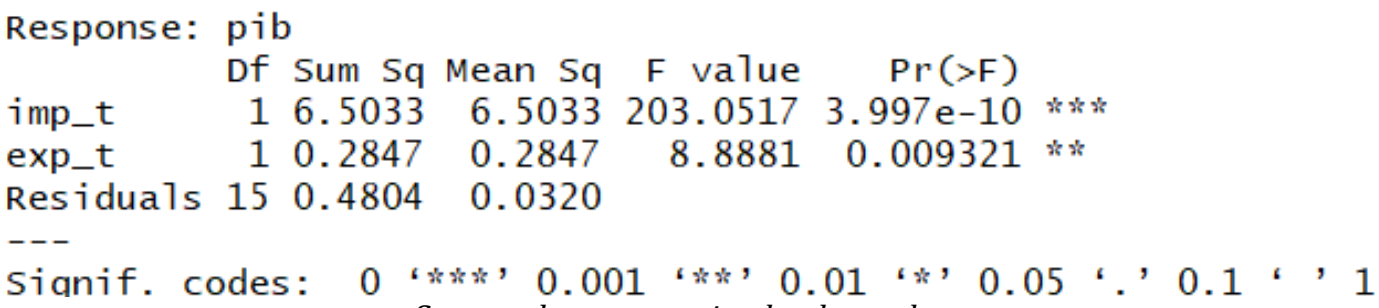

Source: data processing by the authors 
The Anova table (table 2) shows the variance analysis. The object of the Anova test is to see if there is a significant difference between the exports and imports of cereal products. In other words, to find out which of the two economic indicators has a greater influence on the GDP. The Fisher test is used to check the equality of dispersion of the two independent variables. In the case under study the highest value of the Fisher test was obtained $(\mathrm{F}$ value $=203.0517)$, corresponding to the greatest significance for the imports of cereal products.

\section{Conclusions}

As a result of the econometric analysis, we found a regression model based on the Cobb-Douglas production function. Both independent variables are associated to a rather considerable significance, with a value of the comparison between the Std test and its theoretical values close to 0.00 , which is significant. The sum of the values of the indicators exceeds the value 1, so the exports and imports of cereal products accelerate the increase of GDP. One may predict the manner of GDP increase function of the increase of the imports and exports of cereal products. For a $1 \%$ increase of exports the GDP increases by $0.4743 \%$, while for a $1 \%$ increase of imports the GDP increases by $0.747 \%$. in Romania's case, the cereal processing industry has a quite low level. During the past few years, due to foreign investments and the increase in manufacturing line mechanisation, considerable increases of the volume of processed cereal products have been recorded, so that an increase may be felt in the exports of cereal-based processed materials. According to the manner in which imports are reflected in the GDP, it may be concluded that a sustainable economic growth may be obtained from the development of the national cereal processing industry.

\section{References}

1. Bănică, E., Vasile, V., Boboc, C., Romanian Foreign Trade Dependency and Stability, Romanian Statistical Review no. 3 / 2018

2. Gros, V., Produsele cerealiere din România are o pondere de 3,5\% la formarea PIB, capital.ro, 4 October 2016

3. Jemma, D., V., Econometrie, Sedcom Libris, Iasi, 2012

4. Jemna, D., V., Econometrie, "Alexandru Ioan Cuza" University Publishing House , Iași, 2007

5. Joița, R., Top 10 - Cele mai puternice firme din din România, IMOPEDIA.ro, 26 June 2015

6. Jula, D., Jula, D., Structural Breaks in Potential GDP for Romanian Economy; CMSS vol_VI

7. Julia, D., Julia, N. , Structural Breaks in Potential GDP for Romanian Economy, Computational Methods in Social Sciences CMSS, 2018, $p$. 1

8. Macovei, A. G., Balan, I. - Econometric analysis on the influence of different factor over the share of turnover in tourism - The Annals of the "Stefan cel Mare" University Suceava, Fascicle of the Faculty of Economics and Public Administration, ISSN 1582-6554, Year 9, No. 9(1), 2009, pp. 297-306, http://www.seap.usv.ro/annals/arhiva.html

9. Macovei, A. G., Siretean, S. T., Funcţia de producție - factor important în actul decisional, Dezvoltarea turistică regională în Statele Membre ale Uniunii Europene. O abordare cantitativă, Didactic and Pedagogical Publishing House RA, Bucharest, 2017

10. Ministry of Agriculture and Sustainable Development, Raport privind agricultura României în anul 2018

11. FAO, http://www.fao.org/home/en/, last accessed September 3, 2019, 10:30

12. GNU, http://www.gnu.org/, last accessed October 11, 2019, 10:30

13. RStudio, https://www.rstudio.com/products/RStudio/, last accessed October 11, 2019, 10:40

14. PwC Romania, https://www.pwc.ro/en/press_room/assets/2016/wood-industry-ro.pdf 